A year later the lady had a similar attack. Turpenpentine was used but was not successful in dissipating inflammation. There was, however, no suppuration.

Mammary abscess, however, is a comparatively rare affection. It occurs most frequently in primapara, and usually follows a fissured nipple. He thought that physicians should treat promptly all fissures or abrasions upon the breast, and in this way prevent a possible abscess.

Dr. C. E. Hagner said he had had no experience in mastitis, but he agreed with Dr. Busey in the importance of prophylactic measures against abscess. He thought it important to keep the breast from becoming engorged. It ought to be properly supported as soon as milk appears, and after that kept nearly empty. He did not think it rational or according to our knowledge of pathology to suppose that any drug should be so accommodating as to pass through the skin, reach the lacteal ducts, and abort an inflammation, without getting into the milk in the ducts, as was affirmed. Warmth and moisture to relax engorged vessels were necessary in inflammation. For these, and in addition counter-irritation, turpentine might do. Cold or some hæmostatic, as ergot, might do in first stage of inflammation, but beyond that stage he did not believe abortion possible.

DR. S. C. BUSEY said that he thought Dr. Hagner a little "out" in his ideas of the pathology of mammary abscess. There were three forms. The most common was the superficial, in the subcutaneous tissue; then there was the parenchymatous and the submammary. Turpentine put on the skin does not get beyond the subcutaneous tissue, which is absorptive tissue; hence the parenchyma of the gland is not affected. Dr. Hagner says that an hamostatic may be of use. 'Turpentine is an ham ostatic, though he cannot say how it acts. Dr. Hagner also says that he has never used turpentine, but when he has used it as many as thirteen times perhaps he will think better of it. If we exclude drugs whose method of action we are not familiar with, we will have to shorten our list considerably. Thus the method of action of most of the drugs we use externally is unknown.

DR. HAGNER replied that he was not referring in his previous remarks to the submammary and rare forms of abscess, but to the two commoner forms. In the thirteen cases reported by 1)r. Murphy it was by no means certain that pus was going to form. Surely no pus was present in any of them so far as he could see. In fact, some were reported cured of mammary abscess before the usual time for abscess to appear under the circumstances. As for the frequency of this affection, in seventeen years of practice he had had but one case of mammary abscess.

DR. T. C. SMITH asked how the irritation and vesication usual with turpentine on a delicate skin was prevented?

DR. P. J. MURPhy replied that at the first symptom of too severe an irritation the drug was removed or the parts smeared with ointment or oil.

\section{GYNACOLOGIOAL SOCIETY OF BOSTON.}

\author{
Stated Meeting, Octolier 14, 1886.
}

The Prisident, H. O. Marcy, M.D., in the Chalk. H. J. Harriman, M.D., Secretary.

Dr. E. W. Cushing presented a mass of

HYPERTROPHIC RECURRENT GLANDUI.AR TISSUE REMOVED FROM THE VUNDUS UTERI.

This mass of atheromatous tissue filled a four-ounce measure and was recurrent the fourth time. Dr. Cushing called attention to the practical malignity of such growths.

He also exhibited an

$$
\text { OVARIAN CYST }
$$

which was interesting from the fact that it had been diagnosed as a pregnancy by a practitioner of eminence. The tumor was multilocular, and it was with difficulty extracted through a small opening. Dr. Cushing asserted that, in spite of Mr. Lawson Tait's success in operating with an incision of two inches, it was bad surgery to remove a tumor through an opening too small for comfort, and that a large incision, if aseptic, would heal as readily as a small one.

Dr. W. Symington Brown read a paper entitled THE RÔLE OF THE OVARY.

The writer criticised the study of pathology to the exclusion of normal physiological processes. Pathological minutia were compared to the scaffolding about a house during its erection. It serves a practical purpose, but becomes useless after the completion of the building and must be removed, else it will mar the beauty of the structure. More is to be learned by careful observation of natural processes and guarded deductions therefrom, than from the twisted facts which disease presents. For similar reasons the writer attached but little importance to vivisection as a means of discovery. Experiments on living animals may corroborate or test a great disclosure, but seldom or never find one out. 'The changes which the ovary undergoes each month may be called the cycles of involution and evolution. When the latter attains its maximum the ovary becomes nearly twice as large as at the close of involution. The ovary is a gland which secretes free cells. It maintains an intimate connection with many other glands-a relationship more marked during pregnancy, but also noticeable during menstruation. Various glandular diseases, such as jaundice, albumenuria, salivation and mastodynia, may all be dependent on or connected with changes in the ovaryThe more rapid recovery of robust women than delicate ladies from puerperal diseases is attributed to the greater activity of the glandular system in the former class of patients.

The theories of Dr. Noeggerath. of New York, in regard to the widespread and pernicious influence of latent gonorrhœa upon the tubes and ovaries, producing sterility, were referred to with approval. The fact that prostitutes so seldom conceive is without doubt due to salpingitis and periuterine inflammation arising from gonorrhœa. 'This sterility is also often 
found in virtuous women whose husbands are the subjects of a latent gleet and have communicated it to their wives. The fibrous ovarian sheath becomes thickened; the Fallopian tubes are filled with mucopus, or closed, and it is highly probable that the ova themselves never become developed. If both sides are thus affected, sterility is a foregone conclusion.

The removal of the ovaries for metrorrhagia, salpingitis, long-continued agonizing pain or intractable pelvic disease, was discussed. Dr. Brown maintained that the common objection to these operations, that they unsex the patient, was baseless. Sex is not lodged in either ovary or testicle; if it be in one part more than another it is in the brain. A long series of observations had convinced the writer that insanity in women often depends on sexual disorders, and that such cases can only be cured by local treatment. In severe cases of hystero-epilepsy, Battey's operation is conceded by the most conservative to be justifiable.

Reference was made to a class of cases where sterility follows a sudden arrest of menstruation. Whether this unfortunate event is due to the closure of the fimbriated extremity of the Fallopian tubes by a low.grade inflammation, or to arrest of development of ova due to nervous shock, is uncertain.

In considering the question of cases in which menstruation persists after removal of the uterine appendages, attention was called to the possible existence of a third ovary or of single ovisacs in the human parovarium. Where menstruation persists for some months after such operations, it is probably due to the persistence of the original menstrual im. petus. Ovariotomy has proven that the sex of the foetus does not depend upon the particular ovary which furnishes the germ. The determination of sex probably does not depend upon anything done by either party, but occurs long pricr to conception in either the ovary or testicle.

Dr. E. W. Cushins; wished to thank Dr. Brown for his excellent paper. He agreed with him in regard to the importance of gonorrhora as an agent in producing disease of the uterine appendages. 'These results may follow from an old gleet when for years there has been no discharge at the meatus. In many cases the latent gleet can only be diagnosticated by a microscopical examination of the secretions of the urinary tract. In all cases the gronococcus can be found. Dr. Cushing expressed the opinion that nine-tenths of the inflammatory troubles peculiar to women arise from the clap.

DR. I. F. WARner did not believe that a slight gleet often caused ovaritis, metritis, or many of the other diseases so often attributed to gonorrhoea. He did not believe that Noeggerath's views upon that point had ever been generally accepted by the pro. fession.

\section{STATE MEDICINE.}

\section{SANITARY CONVENTION AT BIG RAPIDS, MICHIGAN.}

A Sanitary Convention, under the auspices of the
Michigan State Board of Health, was held November 18 and $\mathrm{I} 9, \mathrm{I} 886$. It was opened by an address of welcome by the Mayor of the city, E. W. Hudnutt, Esq. Dr. John Avery, of Greenville, Mich.; President of the State Board of Health, spoke in response to the address of welcome, and said that the object of the Convention was not to benefit physicians, but the public. The members of the State Board of Health also wished to gain information, that they may better serve the people.

DR. JOHN P. STODDARD, of Muskegon, read a paper on

\section{INJURIES OF EVIERY.DAY DRUG.TAKING.}

He said the habit of taking drugs and nostrums was beyond comprehension. It partly came from mothers dosing babies with soothing syrup, hive syrup, paregoric, worm lozenges, etc. Druggists and pro. prietary medicine companies distributed flaming bills, chromos and free samples of nostrums from house to house. The prevention was to educate the people in the injurious effects of drugs. There should be less medicine taken, and only on the advice of a physician after a careful diagnosis. A doctor was not capable of prescribing for himself when ill, much less the laity, who knew nothing of the action of drugs.

Dr. David Inglis, of Detroit, read a paper entitled

\section{AICOHOI.: WHAT FFFECT HAS IT AS FOOD, MEDICINF} OR POISON?

In closing his remarks on alcohol as a medicine, he said: I should like to produce the continually accumulating evidence of the positive harm caused by such indiscriminate use of all kinds of alcoholic drinks, bitters and tonics. I should like, even more carefully, to define the conditions in which alcohol ought to be used than I have here done. I have only time to urge that we ought, in all cases, to let alcoholic liquors be the last, and not the first, remedy; that we ought to give alcohol in definite and known doses, and only during such time as the drug is required, and to make it our business to see that its use is then suspended, just as we do in case of opium.

DR. J. I. BURKhaRT of Big Rapids, read a paper on the Water-Supply of Bigr Rapids, which embodied the report of the committee appointed by the com. mon council to investigate the matter of procuring a better article of water for that city, and contained much of special interest to the citizens of Big Rapids.

Prof. W. N. Frrris, of the Big Rapids Industrial School, read a paper on

\section{HYGIENE OF SCHOOIS.}

He said that he could not recall ever having visited a room regularly occupied by forty or fifty pupils, that could be said to be properly ventilated. Dulness, nervousness, headache, colds, catarrh and consumption are among the frequent effects of staying in such rooms. Under the influence of bad air, study is irksome, good behavior difficult, and the play-ground a heaven. He dwelt upon the lack of ventilation in the Big Rapids schools; and said that the foul-air openings could be made several times 